\title{
A Study on the Effectiveness of Application of Total Quality Standards on the Sustainability of the Franchise Contract
}

\author{
Ahmed Noman Mohammed Dahan ${ }^{1}$, Muhammed Hafeez bin Zakria ${ }^{1} \&$ Kamal Naji ${ }^{1}$ \\ ${ }^{1}$ Business Administration Lincoln University College, Malysia \\ Correspondence: Ahmed Noman Mohammed Dahan, Business Administration Lincoln University College, Malysia.
}

Received: September 19, 2021

Accepted: November 7, $2021 \quad$ Online Published: November 22, 2021

doi:10.5430/jms.v12n4p17

URL: https://doi.org/10.5430/jms.v12n4p17

\begin{abstract}
This study aims to identify the effectiveness of application of total quality standards on the sustainability of the franchise contract and to identify the difference in the conception of sample about the effectiveness of application of total quality standards. For achieving the objectives, the researcher designed a questionnaire which included the main information and upon the hypotheses, data have been collected and analyzed by using graphs, then, the study concluded the following results; the study pointed out that the application of quality standards has an effective role on the sustainability of the franchise contract, as well as, the study concluded that the application of total quality culture, if applicable, between the parties of the contract raises the percentage of sustainability of the franchise contract. Many results support that the total quality standards have a real relationship with the sustainability of the franchise contract. Many recommendations have been proposed at the end of the article.
\end{abstract}

Keywords: quality, sustanability, contract, franchise

\section{Introduction}

The interest of quality has become a global phenomenon and the organizations in the world are paying special attention to it. Quality has become the first function of any organization, management philosophy and lifestyle for any organization to enable it to obtain a competitive feature that enables it to survive and continue in the light of successive fast changing environmental changes, and the emergence of global markets, the increased consumer demands for quality and intensification of competition, resulting in that quality became a strategic weapon to gain competitive feature.

Recognizing the importance of quality as a strategic weapon to gain a competitive feature has led to adoption of the philosophy of Total Quality Management, It is a philosophy based on a group of special ideas for looking at quality on the understanding that it is a process of integrating all the activities and functions of the institution that related to access to a distinct level of quality. Quality becomes the responsibility of every individual in the institution, which maximizes the performance of the institution.

\subsection{Importance of Study}

The concept of Total Quality Management is a modern management concepts which has become the focus of many researchers, scholars and practitioners (Al-Nasser, 2010, 39). It has also become the basis of this concept and its methods which are represented in:

Attention to the beneficiary and quality control through statistical processes and necessity to provide the organizational culture that supports the change is the basic framework of the management style in many organizations of the developed countries, this new interest in terms of management concepts has no similarities in the Arab environment as our styles in many of our organizations still apply the bureaucratic approach in the management, which in turn resulted in the aggravation of administrative problems and bad services provided and thus the beneficiary's dissatisfaction from the production or services. From this point, Arab organizations started to recognize the importance of introducing the concept of Total Quality Management (TQM) to improve the performance and develop productivity by building a deep culture of quality and attention towards customer.

Through the researcher's knowledge of many of the franchises that did not achieve success because of its failure to apply the standards of comprehensive quality, whether by the franchisor or franchisee. 


\subsection{Theoretical Importance}

The theoretical importance of this study is derived from the importance of the subject addressed by the fact that the topic of Total Quality Management is one of the most important fifteen administrative entrances that has been and continues to receive great attention from those who are interested in this field where the progress of the societies and the development of their organizations and their continuity depends mainly on contemporary entrances, its moving and chart its plans and policies. This entrance has many applications for improving the performance of organizations in general and development it.

What makes this study more important is the Franchise industry global which witnesses steady and stable growth. The market in the Middle East and North Africa is witnessing a big boom and has grown rapidly in which the investment at franchises in the Middle East reaches more than \$ 30 billion (Middle East Association of Franchise, 2017) sometimes the franchisor may resort to annulment the contract because the franchisee has not complied with the standards that were required in the contract and vice versa. The franchisee also resorts to the cancellation of the agreement for the same reason.

From the point of application, the researcher finds that the study will help entrepreneurs and investors choose the companies that franchisor the franchise based on full knowledge of quality requirements. This guarantees their continuity in safe investment.

It will also contribute to the definition of official bodies concerned with quality and excellence with the most supreme obstacles and methods of training and development.

\subsection{Study Problem}

The franchise contract became present in most production and service industries as a safe investment system. The franchisee believes that it would proceed with a similar success to the success of the Franchiser Institution. However, through the practice of the business, it may face problems that lead to the closure of this investment and turn successes into losses and problems between the franchisor and franchisee some of them are related to the Franchisor and others to the Franchisee. Therefore, the researcher saw that the problem of study should be the extent of effectiveness in applying the Total Quality Management standards in the sustainability of franchise contracts

\subsubsection{Research Questions}

The main question might be how effective is the application of Total Quality Management in the sustainability of franchise contracts. This question includes several questions:

- What is the relationship between the application of quality standards and the sustainability of the franchise contract?

- What are the tendencies of the franchisees for franchise towards the application of quality standards?

- What are extent to which the brand owners of the franchisee support the application of quality standards?

\subsubsection{Objectives}

- Knowing the relationship between the application of quality standards and the sustainability of the franchise contract.

- Identifying the extent of the franchisee tendency towards the franchise in the application of quality standards.

- Stating the importance of Supporting Brand Owners for franchisee in application of standards.

\section{Literature Review}

\subsection{First Section: Definition of Total Quality}

It has been defined as the ability of the product or service to satisfy the customer's needs and these needs are either declared or latent.

Hygan (1994) has defined it as the client performance correctly from the first time, relying on the customer's evaluation to know the improvement of work.

El-Ibrahim 1998 defined as the efforts of doing by the management of the institution in a cooperative manner to accomplish the business that depend on the abilities and talents of both the management and the employees to improve the quality and productivity continuously through the team work and is guided by accurate and objective information to get rid of all forms of waste in the institution. 
Goran said that quality is the appropriateness for usage.

Crosby defined it as 3 conditions:

1. Fulfillment of the requirements.

2. No defects.

3. Perform the work properly from the first time.

Dyming defined as the achievement of needs and expectations of the beneficiary in the present or in the future.

It is doing the right things through the right method to reach the desired target.

The concept of total quality management from the point of view of the researcher is based on the words of the Prophet peace be upon him (that God loves if one of you do work should be perfectly) Fath Al-Bari 880 and perfecting the work in the guidance of the Prophet includes all the works that our religion urges, which begins with monitoring the human Lord during his work and finishes with the completion of work perfectly. From the above, it is clear that there are multiple definitions of total quality management because each writer and researcher sees the topic from the aspect that focuses on certain aspects he deems them to be important, but despite the differences in the definitions there are points where all the definitions meet in; for example:

\section{Continuous improvement}

\section{Satisfying customer needs and desires}

Focusing on the processes rather than the product.

Total quality standards

\section{Quality standards}

There are many standards that the institution is supposed to adopt it for achieve its long-term goals, which are:

\section{Employee participation:}

Quantitative and statistical indicators have confirmed that $85 \%$ of the problems related to quality are mainly due to raw materials and operational processes. Therefore, it is practically recognized that the participation of workers and giving them the right to act in making decisions would achieve the targeted dimensions to reduce those problems. There is no doubt that the Japanese have been able to achieve tangible advantage by adopting the method of full participation for employees. This approach is one of the main pillars that should be adopted in the application of total quality management. The launch of events, promotion of innovation and creativity, the creation of training, developmental and incentive programs, planting the spirit of self-participation, strengthening the spirit of one team, are essentials in the case of strengthening organizational structure, and to achieve optimal goals, which various humanitarian organizations seeks to achieve (Dean and Evans, 1994).

\section{Training and education:}

The consumer society is generally characterized by rapid change and the growing need for consumer desires and aspirations that comes from rapid changes in tastes, needs and requirement. Therefore, the institution that is characterized by flexibility and rapid response to consumer variables has broad dimensions of success in meeting consumers' needs and growing aspirations in this particular. Therefore, one of the fundamental pillars of modern total quality management is the rapid response to meet the needs and desires of existing and prospective beneficiaries. This trend, in achieving this, is only through the continuous pursuit of training and educating employees on basis guarantee the response to the needs of current and prospective beneficiaries and to satisfy their aspirations in this regard.

The objective contribution to the development is considered one of the basic activities adopted by the total quality management system, especially since the contribution of the employees and giving them the right to act in making decision related to performance, each through his responsibility and his work make the ways of development and contribution in it a practical situation. In addition to the development of disposition, capabilities and skills through the continuous education and training developmental courses is a basic condition required by different organizations in order to achieve its objectives efficiently and effectively. (Summers, 2000)

\section{Communication System in institution:}

Making right and scientific decisions cannot be achieved without resorting to the adoption of objective and realistic facts, especially since this trend is one of the most important activities aimed at enhancing the success of total quality 
management, this, in turn, requires the provision of an effective information system and communication systems with objective purposeful dimensions. It also depends mainly on human forces that are more capable of perceiving facts and embodying them practically. Therefore, the communication system in the institution is considered one of the most dimensions to achieve the ways of adopting the total quality which focuses, on their ways to success, in adopting objectivity, clarity and transparency in communication systems (Aloush, 1997).

\section{Focus on beneficiaries:}

The beneficiaries of services provided to them by the institutions are the main focus of the activities related to total quality management. This is illustrated by many indicators; for example, (International Malcolm Baldrig) award granted $25 \%$ of its brands to the interest of the institution in its customers, and fulfilling their desires. The beneficiary of the services, provided under the concept of total quality, includes both internal and external beneficiaries. The definition of external beneficiary is the individual in which all the activities and efforts are centered around in order to achieve his desires and motivating him in the acquisition of the provided product or service ... etc. The internal beneficiary represents the individuals working in the different organizational and technical units in the same institution, such as the employees in (units, departments, service divisions, circles, etc.), where these individuals are usually viewed as beneficiaries who will supply their previous operations and suppliers to the departments that achieve their service achievements.

\section{Using the Scientific Method in Making Decisions}

The scientific method in making technical, administrative and organizational decisions is one of the most important decisions required by administrative work, especially with regard to the design of the product and ways to match it with the achievement to be achieved. Decisions related to this direction are of great priority in this regard, so product design processes are one of the most meaningful prospects in performance. Therefore, the accuracy of the match between the design and the performance achieved cannot be done without the design being able to execute on the one hand, and have criteria and standard specifications that are clear in dimensions and landmarks, on the other hand. This is one of the most important factors in achieving the success and effectiveness of the total quality management system. Therefore, there are three basic dimensions: (Goetsch and Davis, 2000)

1 - Quality in design.

2- Quality in performance.

3- Quality in conformity.

These dimensions cannot be achieved without reliance on meaningful scientific decisions.

\section{Using methods and statistical methods in quality control:}

Decisions related to quality are considered strategic decisions. Therefore, the leadership of the management plays a crucial role in supporting and revitalizing the movement of the worhers in the operational performance. The leadership plays an active role in this regard, especially if the management leadership in the institutions focuses on the adoption of scientific methods in the performance achievement. Among the most common scientific methods and used in total quality management are: statistical methods in quality control, which is now one of the most effective ways of improvement and development (Goetsch and Davis, 2000).

\section{The long-term commitment of institutions to continuous quality and improvement:}

The long-term quality commitment is one of the basic principles emphasized by the ways that lead to the continuous development and improvement. Therefore, the continuous improvement is one of the most effective ways of development and improvement. The adoption of rigorous scientific method in the continuous improvement and development in the operational performance of the production processes is one of the most fundamental and important methods to improve the product and its relevance to the continuous developments and changes in the growing needs and desires of the beneficiaries. The continuous improvement of performance requires a rapid response to changes, on the one hand and a simplification of procedures and operational events, on the other hand. Therefore, there is an integral relationship between quality and the rapid response to development and productivity. The criterion of integration must be taken into consideration while adopting any change or targeted development (Al-mzyd, 2013).

\section{Unity of Institution Objectives and Employees:}

The management of human resources in the institution has a great priority in energizing and activation of total quality management. The promotion of the spirit of collective responsibility and deepening the spirit of belonging 
would contribute to the strengthening human skills and competencies and training, developing and motivating it. Also they contribute to the creation of the basis that are capable bring success to the institution and achieve its objectives, and to

show the images of family work, strengthening the spirit of organic connection of the individual in the group (Working Group) and institution, since the focus on the spiritual aspect to reach high levels of quality is one of the pillars that has led to the distinction of Japanese society and given them shining image among different human societies.

\section{Principles of Quality Management}

\section{1). The Focus on the client}

This focus is not only confined to the external customers of the institution that it devotes all its time and effort to motivate them to purchase its products, but also includes the employees within the institution, who achieve the required quality level depends on their performance.

Benefits of achieving this principle:

Increasing profits and market share. -

Increasing efficiency in the use of the institution's resources. -

Increasing customer and employee's loyalty. -

\section{2). Leadership}

Leadership is responsible for establishing the unity of purpose and direction of the institution, and they should create and maintain the internal environment appropriate for the employees to participate effectively in achieving the goals.

Benefits of applying this principle:

Employees' understanding and enthusiasm for the policies and objectives of the institution.

- Reducing the opportunities for misunderstandings and poor communication between different levels to possible minimum.

\section{3). Employees participation}

Traditional administrative concepts assume that the labor force consists of individuals who have no mind and are only interested in getting paid. However, under the concepts of total quality management, financial compensation is one of the ways in which employees can be rewarded. Studies have shown that employees do not consider remuneration the only incentive, but rather that they should be commended for their efforts, then they should notify them. The labor force is a huge mine filled with information, opportunities that can be used to develop work, increase production and reduce costs. Employees must therefore be notified that they are members of a winning team.

Benefits of achieving this principle:

Innovation and creativity among employees.

Enthusiasm to participate in continuous improvement.

\section{4). Process Methodology}

The desired result can be achieved more efficiently when resources and related activities are managed as a process.

Benefits of achieving this principle:

- Reducing costs.

- Improving results.

\section{5). Continuous improvement}

Continuous improvement of overall performance must be a constant objective of the institution.

Benefits of applying this principle:

- Characterizing Performance through improvement.

- Flexibility to interact with new opportunities. 


\section{6). Making decision based on practical evidence}

Effective and successful decisions must be based on data analysis and information.

Benefits of achieving this principle:

- Wise decisions.

- Ability to demonstrate the effectiveness of decisions by reference to the facts registered.

\section{7). Relationship Management}

The institution and the resource depend on each other and the mutual interest between them increases their ability to find benefit.

Benefits of achieving this principle:

- Increasing the ability to find the benefit for the two parties.

- Flexibility and speed for joint response by both parties for market conditions changing.

\section{Benefits of quality application}

The application and use of certain management principles and concepts cannot be of interest to high management unless they result in the achievement of certain benefits and the application of concepts and principles of total quality management, leading to the achievement of many benefits, most notably are:

1. Improving the quality of services

2. Raising employees level of performance

3. Reducing service and operating costs

4. Working on improving and developing ways and methods of work

$5 /$ Increasing the loyalty, affiliation and satisfaction of employees in the institution

There are benefits acquire by employees in the institution as a result of their commitment to the application of total quality management including:

- Developing the skills of the employees in the institution through their participation in developing the methods and procedures of work in the institution.

Giving employees incentives as a result of efforts to do their work.

Providing the organizational climate that adapts with the institution and its objectives.

\section{Elements of Quality management}

Through the acquaintance of the researcher for the literature review about the elements of total quality management and what the researchers reported on this, he found that there is no total agreement about the elements, which makes the study of all the elements impossible and outside the framework of this study. The researcher cited these elements based on what most studies agreed upon and they are:

\section{1). Sharing Employees in Making Decision}

The participation of employees in making decision will undoubtedly encourage the employee to work with an open mind because he will not work as a machine and this leads to encouraging creativity, raising morale and leads to a greater degree of belonging to the organization and commitment to work.

\section{2). Create Teams to Improve Work}

It is to form teams work from workers themselves to analyze the work they do from work for the purpose to continuously improve the works they do, taking into account that productivity is improved through the improvement of the atmosphere in an administrative environment that enables employees to inform management of the truth.

\section{3). The ability to change}

We are living an age characterized by continuous change, change in the level of technologies used and other changes in all aspects of life. The ability to change has become a component of total quality management because it concerns with the change in the levels of performance and improvement, the organizational environments and management philosophies that it is based on. 


\section{4). Customer subscription}

The importance of customer participation in the making decision process stems from the fact that the customer is the one who values the quality, and that the employees do not accept the idea that the customer will ultimately value the quality of the product. So it was necessary to know the needs and desires of the client and give him the opportunity to express his opinion.

\section{5). Solving problems through preventing it from occurring}

The total quality management aspires to continuous improvement and to prevent problems before they happen. This will only be done through proper planning, which seek always to study, analyze and predict what will be in the future. Through this planning process, the expected problems will be studied in a scientific manner, followed by specific steps, and suitable solutions will be developed among the options and alternatives available. Thus, The Total Quality Management reach to avoid problems before its occurrence.

\section{6). Training and developing to improve quality}

The Total Quality Management implementation requires attention to training as a key factor in the development of employee's skills and behavior. Training on quality should be extended to all employees of the institution and not only limited to quality employees of service or product which he offers the project closure phase.

\subsection{Second Section Introduction}

He boom in franchising did not take place until after World War II. Nevertheless, the rudiments of modern franchising date back to the middle Ages when landowners made franchise-like agreements with tax collectors, who retained a percentage of the money they collected and turned the rest over. The practice ended around 1562 but spread to other endeavors. For example, in 17th century England franchisees were granted the right to sponsor markets and fairs or operate ferries. There was little growth in franchising, though, until the mid-19th century, when it appeared in the United States for the first time.

One of the first successful American franchising operations was started by an enterprising druggist named John S. Pemberton. In 1886, he concocted a beverage comprising sugar, molasses, spices, and cocaine (which is no longer an ingredient). Pemberton licensed selected people to bottle and sell the drink, which is now known as Coca-Cola. His was one of the earliest - and most successful — franchising operations in the United States.

The Singer Company implemented a franchising plan in the 1850 s to distribute its sewing machines. The operation failed, though, because the company did not earn much money even though the machines sold well. The dealers, who had exclusive rights to their territories, absorbed most of the profits because of deep discounts. Some failed to push Singer products, so competitors were able to outsell the company. Under the existing contract, Singer could neither withdraw rights granted to franchisees nor send in its own salaried representatives. So, the company started repurchasing the rights it had sold. The experiment proved to be a failure. That may have been one of the first times a franchisor failed, but it was by no means the last. (Even Colonel Sanders did not initially succeed in his Kentucky Fried Chicken franchising efforts.) Still, the Singer venture did not put an end to franchising.

Other companies tried franchising in one form or another after the Singer experience. For instance, many decades later, General Motors Corporation established a somewhat successful franchising operation in order to raise capital. Perhaps the modern franchising father franchising, though, is Louis Kroh Liggett. In 1902, Liggett invited a group of druggists to join a "drug cooperative." As he explained to them, they could increase profits by paying less for their purchases, especially if they set up their own manufacturing company. His idea was to market private label products. About forty druggists pooled $\$ 4,000$ of their own money and adopted the name "Rexall." Sales soared, and "Rexall" became a franchisor. The chain's success set a pattern for other franchisors to follow.

Although many business owners did affiliate with cooperative ventures of one kind or another, there was little growth in franchising until the early 20th century, and what franchising there was did not take the same shape as it does today. As the United States shifted from an agricultural to an industrial economy, manufacturers licensed individuals to sell automobiles, trucks, gasoline, drinks, and kinds of other products. The franchisees did little more than sell the products, though. The responsibility sharing associated with present franchising arrangement did not exist to any big extent. Consequently, franchising was not a growth industry in the United States.

It was not until the 1960s and 1970s that people started to take a close look at the attractiveness of franchising. The concept intrigued people with entrepreneurial spirit. However, there were dangerous pitfalls for investors, which almost ended the practice before it became truly popular. 


\subsubsection{Definition of Franchise}

Achieving franchise, as a work system and an innovative way to exploit commercial industrial property rights, additional income for the franchisor, represented in the financial consideration which gets it peer for the exploitation of the trademark ownership right, and reduce the performing cost its business, in addition to getting spread at low cost. In addition to that, also there is flexibility in work and a high degree of transparency between the franchisor and franchisee. Also achieve the financial, marketing and administrative benefit to licensed institutions and reduces the risk degree faced by franchisees in the institution and projects operation as a result of the advantages acquired and provided by franchisees such as establishing activity in good experienced and developed methods, as well as benefiting from the practical experience of the Franchisor in the marketing and administrative fields. In addition to this, the consumer who has achieved this innovative method has his desires and needs, he can purchase international products at a lower final cost, while protecting against deception and commercial manipulation by imitating famous brands and the consequent losses and risks paid by the consumer and the local economy as well.

It is estimated that franchises represent $50 \%$ of the world's retail business models. In the Saudi market flourishing franchise, there are about 800 companies eligible for commercial franchise, the franchise provides an integrated system of production, marketing and distribution of goods and services.

Here we address the definition of Franchise. Many unions and associations specialized in the field of Franchise have adopted a definition of the franchise system. Some dealt with it as a system and modern commercial style, others have defined it as a contract like innovative commercial contracts. In addition to their definition of franchise, they set different parameters and controls which the exercise of franchise activity is based on, through issuing a codification of the conduct and ethics that has to be made by parties of the contractual relationship established for the franchise agreement hast to be take into account and comply with it.

For some of these definitions, we will show what franchise is before going into its legal aspects.

The French Franchise Association defined Franchise as "a way of cooperation between two projects, the Franchisor, and the Franchisee, which include:

Ownership or right to use brands to attract customers, whether trade brands, industrial $\bullet$ names, logos, company name, trade name, or symbols.

- Use of technical knowledge and its own acquired experience.

- A range of products and / or services or technology.

The connect between these elements constitutes the concept of Franchise "(Al-Hadidi, 2006, p. 19).

This definition is considered to be collector and comprehensive of all elements of franchise such as a system British Franchise Association.

The British Franchise Association defined a franchise contract as a contract between a person called the Franchisor and another person whose Franchisee according to which the franchisee is allowed to exercise during a certain period in particular work under a certain name own for franchisor or associated with him, where the franchisor exercises a continuous control and censorship during the term of the license of the works which are performed by the franchisee and constitute the subject of the license. The franchisor is obliged to provide the franchisee with all necessities to perform the work of the license and to assist him in doing it particularly (organization of work, training, management, etc.), The franchisee is compelled to pay the franchisor during licensing period the license fees and commissions payable due to sales he performed.

Franchise is also defined according to the International Franchise Association (IFA) as a contractual relationship between the franchisor and the franchisee where the franchisor shall provide the technical knowledge and training to the franchisee who carries out the work under a trade name and form or procedures owned or controlled by the franchisor, under which the franchisee invests his own funds in the work licensed to him.

The European Franchise Federation (EFF) defined the franchise as: "A system for the marketing of goods, services or technology based on permanent and close cooperation between two financial and legal parties, the franchisor on the one hand and the recipient on the other under which the first is grants- directly or indirectly - the right to the second party to perform the work in a special method, using the name, trademark or service mark, as well as technical knowledge, commercial and technical methods, procedural systems and its other particular intellectual and industrial property rights, supporting that by commercial and technical assistance for the duration of the Agreement Franchise concluded for this purpose. 
In the opinion of the researcher that this definition is the most focus and comprehensive definitions, since it includes all elements of franchise. It also dealt with the franchise contract from a legal perspective. In the legislative side, the Financial Markets and Services Act provides that a franchise contract is "an agreement under which a person gains profit or income through the exploitation of the right granted by agreement including the trade name, design or any intellectual property rights or goodwill associated with it.

\section{Advantages and disadvantages of franchising as an entry mode}

Franchising brings with it many advantages and disadvantages for companies looking to expand into new areas and foreign markets. The main advantage is that the company does not have to bear the development cost and risks of opening a foreign market on its own, as the Franchisee is typically responsible for those costs and risks, putting the onus on the Franchisee to build a profitable operation as quickly as possible. Through franchising a firm has the potential of building a global presence quickly and at a low risk and cost.

An essential disadvantage to franchising is quality control, as the franchisor wants the firm's brand name to convey a message to consumers about the quality and consistency of the firm's product.

They want the consumer to experience the same quality regardless of location or franchise status.

This can confirm to be an issue with franchising, as a customer who had a bad experience at one franchise may assume that they will have the same experience at other locations with other services. Distance can make it difficult for complain to detect whether or not the franchises are of bad quality or not. One way around this disadvantage is to set up extra subsidiaries in each country or state in which the firm expands. This creates a smaller number of franchisees to oversee, which will reduce the quality control challenge.

\subsubsection{Characteristics of Franchise}

Through the mentioned definitions, a set of distinguishing characteristics can be explored in the franchise contract which forms the common denominator between these definitions so that we can describe this contract as:

\section{1). Contracts Necessary for Both Sides:}

Which binds two persons (natural or legal persons) who enjoy financial and legal independence, whereby the franchisor is committed for franchisee a set of obligations?

The franchisee is committed for franchisor a set of obligations that will be mentioned later in this study.

\section{2). Compensation contracts:}

Because the two parties of the contract take compensation from one another. The franchisor enables the franchisee to exploit both the trademark and the technical knowledge and technology owned by him, on the other hand, the franchisor benefits from the financial compensation specified in the contract.

\section{3). Time contracts:}

The franchise contract is a time contracts related to continuous implementation. In this regard as the contract of supply in which a contractor is committed to provide the other contractor with something specific that is repeated over a period of time.

For the reference, the determination of duration in the contract is often in favour of the franchisor for protection, especially in case if the investment is expensive.

\section{Technical Knowledge and technology:}

Technical knowledge is the essence of the concession contract and the comitedary line between this kind of other contracts similar to it such as the contract of licensing and distribution contract so that the franchisor commitment to transfer the technical knowledge to the franchisee is a condition and attribute closely to the Franchise contract and consequently result in the loss of this privatization. This contract is converted from a Franchise contract into a distribution contract or a commercial license contract.

\subsection{Obligations of Contract's Parties}

The first is committed to transfer the components of the technical knowledge to the second, is committed to the space, is committed to main tain the confidentiality of the improvements introduced, is committed to provide technical assistance and transfer of improvements, and is committed to guarantee. These obligations are offset by the franchisor obligation to perform in return for the technical knowledge he obtains, is committed to maintain its confidentiality, and is committed to efficiency and the maintenance of the class of production and, finally, he is obliged to disclose the provisions of national law. These obligations will be address in research and studied as 
follows:

\section{Research Methodology}

3.1 Statistical Analysis

\section{: Sector ribit}
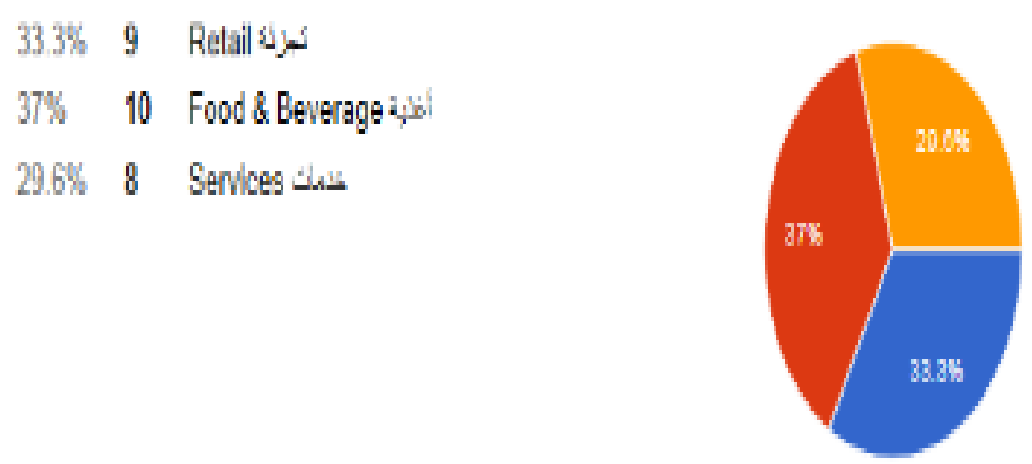

Figure 1. The rapprochement of sectors in the field of investment

Figure 1 shows the rapprochement of sectors in the field of investment, where the food sectors by $37 \%$ and perhaps the reason for this return to the turnout of foods permanent so the investment in this sector is Semi-guaranteed.

However, the retail sector of all kinds came in second rank by $20 \%$, perhaps the reason for return to the knowledge and experience that are a hindrance in the transfer of the franchisee.

The services sector came in third rank by 33\%. This sector was explained in the theoretical framework. Perhaps the reason for this return to this sector which is the less grants because the investment in it requires big capital, which makes it limited to a certain class of businessmen.

\subsection{Franchisor ets \\ 41.7\% 10 Franctigee}

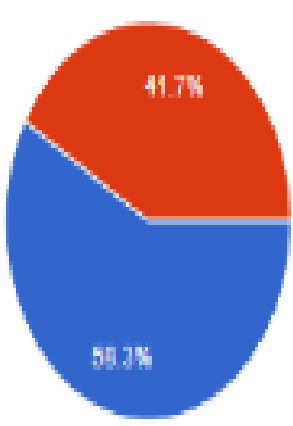

Figure 2. Percentage of franchisors who responded to the questionnaire

This Figure 2 shows that the percentage of franchisors who responded to the questionnaire was $58 \%$ versus to $41 \%$ of the franchisees 


\section{Kind of Grants}

The Existence of an Advertised Organizational Guide that has an Impact on the Sustainability of the Franchise Contract
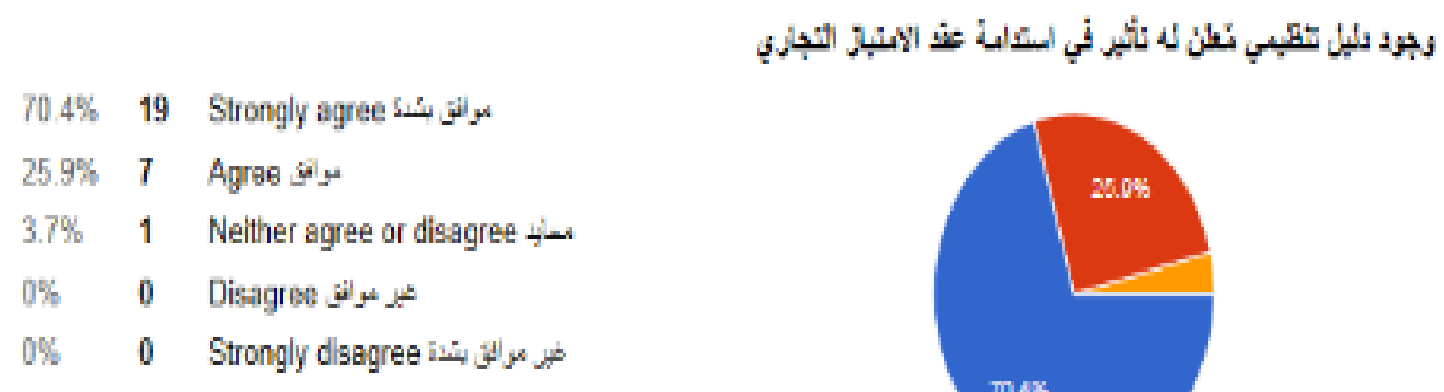

Figure 3

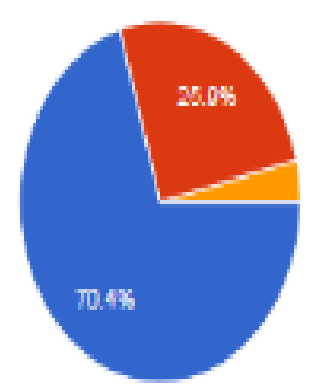

Figure 3 indicates the variation in percentage of response to the question: the existence of an advertised organizational guide Does it affect the sustainability of the contract? Which the strongly agree came in a percentage exceeded by $77 \%$, while the disagree and the strongly disagree came at the last rank in a percentage of zero, the neutral came in the third rank by $3 \%$, and perhaps the strongly agree by sample on this allotment due to the importance of the existence of the guide and its announcement.

\section{Adopting the Concept of Continuous Improvement Contributes to the Survival of the Franchise Contract.}
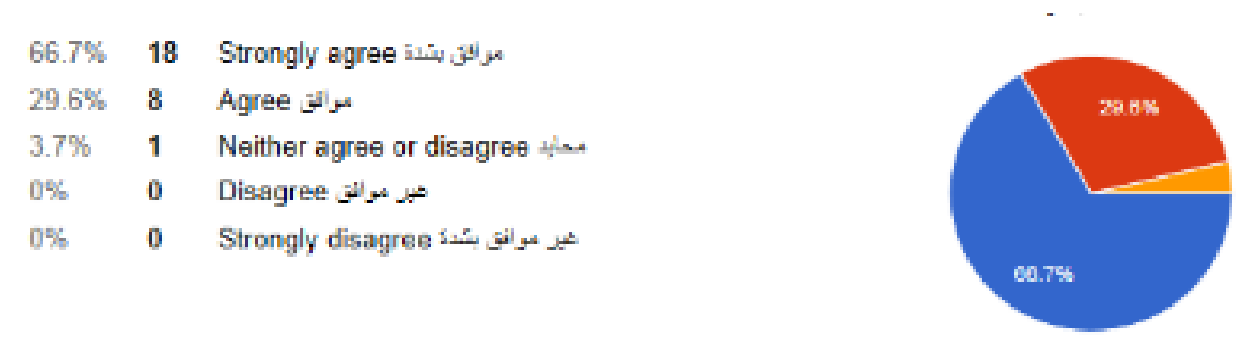

Figure 4. Concept of continuous improvement in the institution

Figure 4 indicates the variation in percentage of response to the question: Does the concept of continuous improvement in the institution contribute to the survival of the franchise contract? Which strongly agreed in a percentage exceeded $66 \%$, while the disagree and the strongly disagree came in the last rank in a percentage of zero, the neutral came in the third rank in a percentage of 3\%. This is due to that the concept of continuous improvement is one of the most important principles that an institution must adopt.

\section{Having a strategic plan with the franchisor makes it easier for the franchisee to apply quality standards}

Figure number 5 indicates to sweeping the answer to the question: Having a strategic plan with the franchisor makes it easier for the franchisee to apply quality standards or no? Which the strongly agree came in a percentage of exceed $92 \%$. While the disagree and strongly disagreed and the neutral came in the last rank in a percentage of zero. The agree came in the second rank in percentage $7 \%$.

Lack of interest in the franchisee teamwork by the franchisor affects the sustainability of the franchise contract 

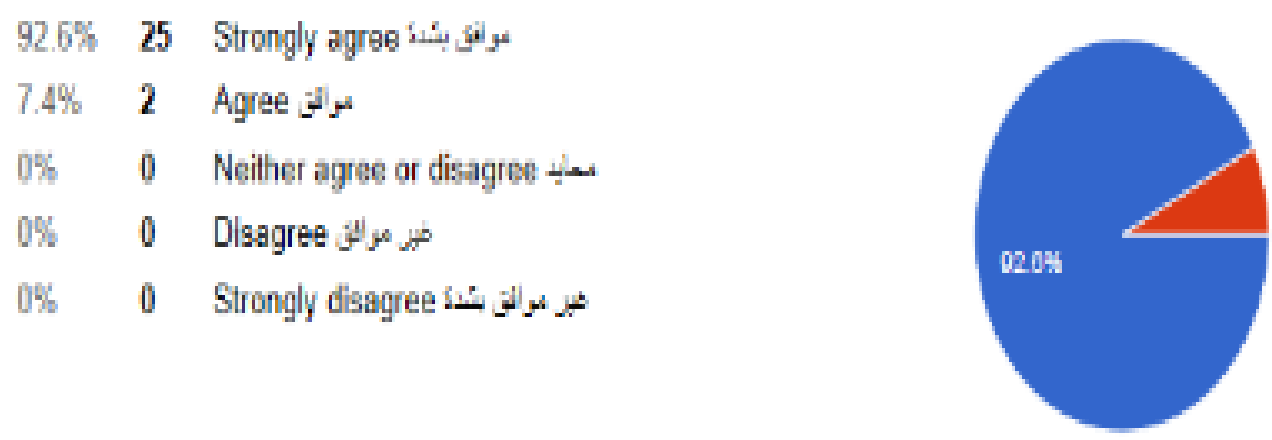

Figure 5.5 indicates to sweeping the answer to the question
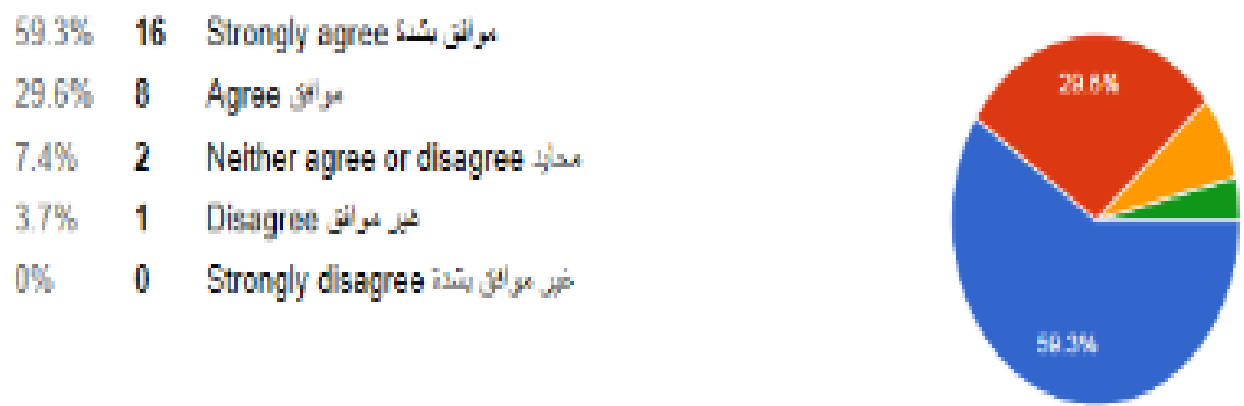

Figure 6

Figure number 6 refers to the variation in the percentage of response to the question: Lack of interest in the franchisee teamwork by the franchisor affects in the sustainability of the franchise contract? Which the strongly agree came in a percentage exceed 59\%, while the strongly disagree came in the last rank in a percentage of zero, the neutral came in the third rank in a percentage of $7 \%$. The agree came in the second rank in a percentage of $29 \%$. This is due to one of the most important factors contributing to the sustainability of the contract and attention to the teamwork.

Specialization of management to follow the application of the franchisee to quality standards
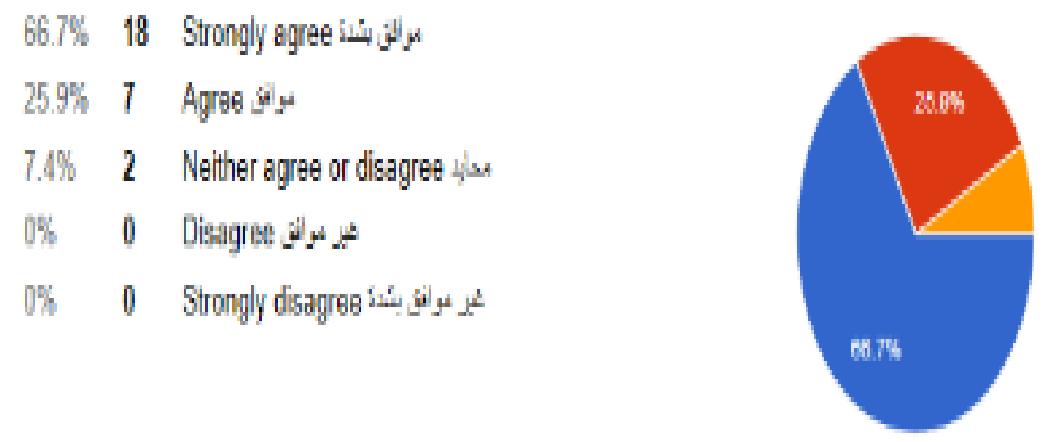

Figure 7 
Figure number 7 indicates to the variation in the percentages of responses to the question: specialization of management to follow the application of the franchisee to quality standards by the study sample, which agreed the specialization of management to follow up and strongly in a percentage exceed $66 \%$, while the disagree and the strongly disagree came in the last rank in a percentage of zero and the neutral came in the third rank in a percentage of $7 \%$. Perhaps the strongly agree from the sample on this specialization due to the fact that the competent management will be familiar with all matters and will result in the continuity of contract.

Achieving a high percentage of sales makes commitment to quality standards a secondary matter
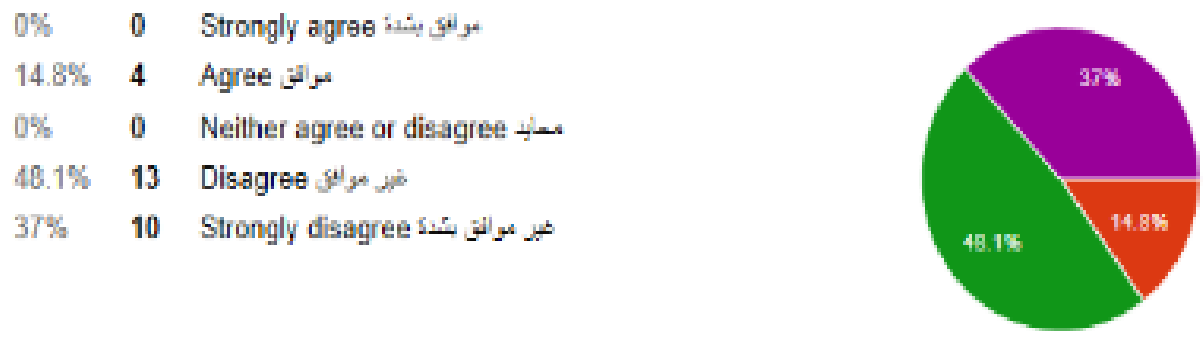

Figure 8

Figure number 8 refers to the variation in the percentage of response to the question: Achieving a high percentage of sales makes commitment to quality standards a secondary matter, which the strongly disagree had the highest share by $48 \%$ and the agree in the third by $14 \%$.

Franchisee application to culture of customer satisfaction, firstly contributes to the continuation of the contract
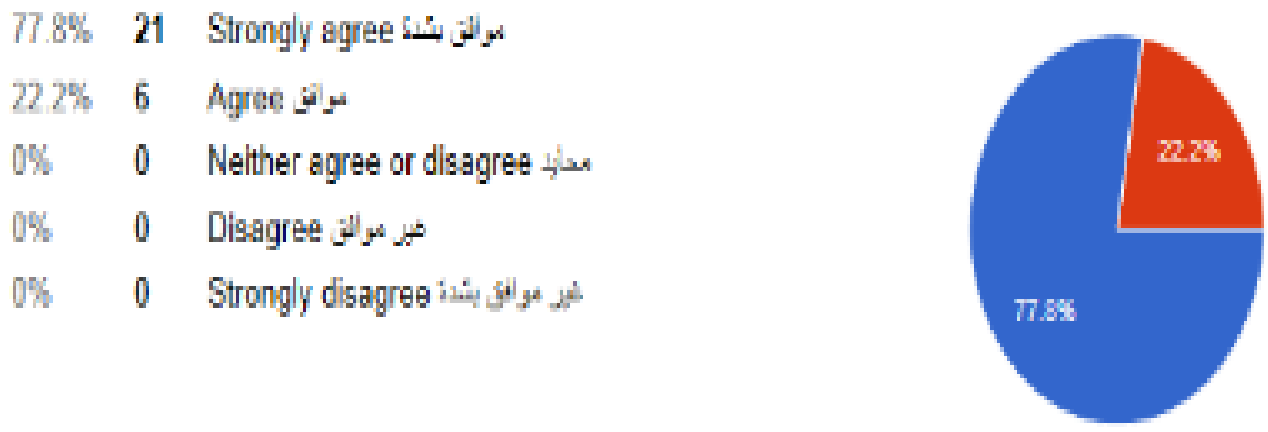

Figure 9

Figure number 9 refers to the variation in the percentages of responses to the question: does franchisee application to culture of customer satisfaction, firstly contributes to the continuation of the contract or no? Which the strongly agree came in a percentage exceed $77 \%$, while the strongly disagree and the disagree and the neutral came in the last rank in a percentage of zero. This is due to one of the most important principles of quality that is the customer satisfaction.

\section{A quality culture that was known to the franchise and the franchisor will help to apply the standards}



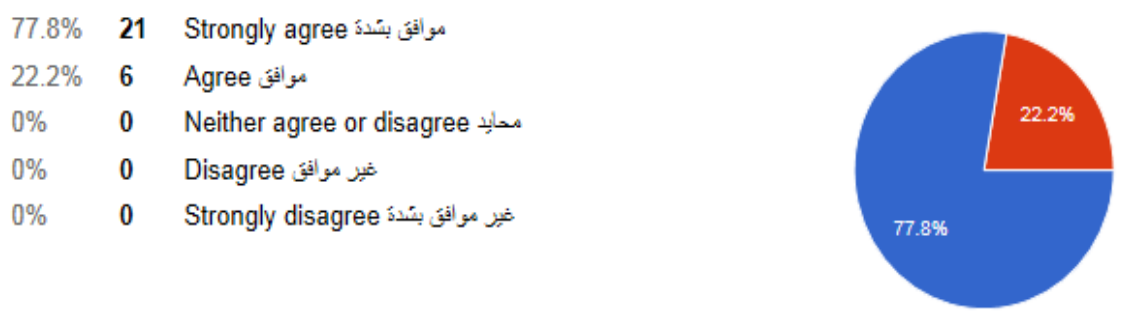

Figure 10

Figure number 10 refers to the variation in the percentages of responses to the question: If the quality culture was known to the parties of contract, it will help apply quality standards? The answer was strongly agreed in the first rank by $77 \%$. This is due to declaring that both parties of contract must have full confidence in quality.

The imposition of censorship and following-up will be a reason for not continuing the contract

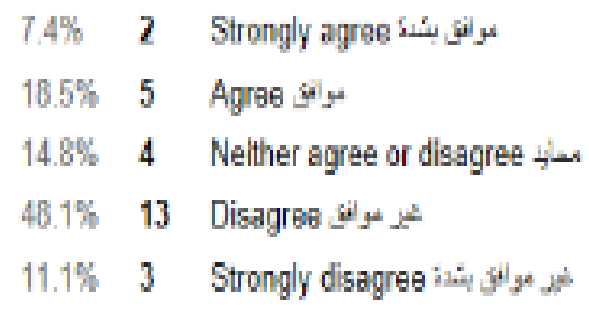

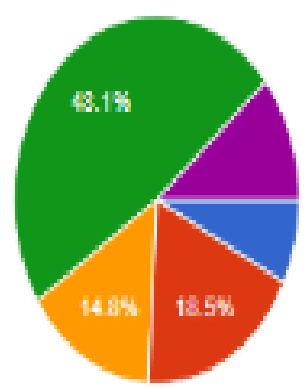

Figure 11

Figure number 11 refers to the variation in the percentages of responses to the question: imposition of censorship and follow-up will be a reason for not continuing the contract?

The percentage of those who answer disagree was $48 \%$ and in second rank came the group who answered in the agree by $18 \%$, while the rest of the percentages were distributed among the other groups. This is due to the understanding of each group to the nature of the imposition of following-up and its mechanism and whether it will be an obstacle or contribute to the continuation of contract.

\section{The contribution of the franchisor to educate the franchisee about quality and its standards}
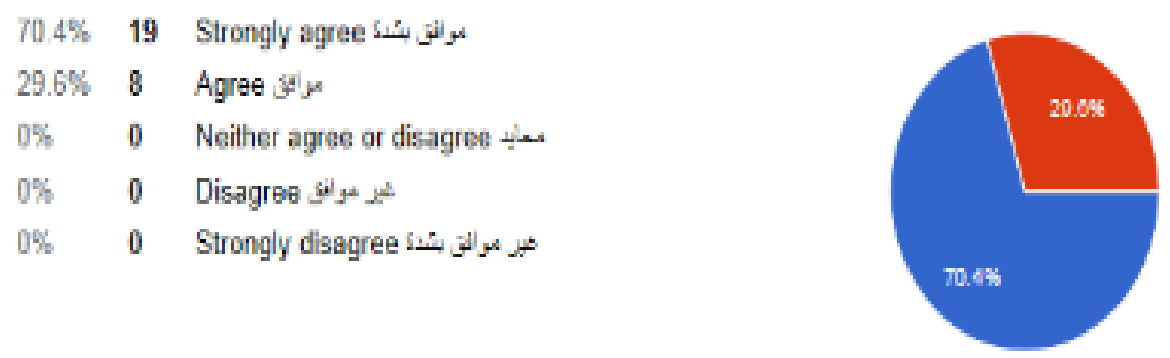

Figure 12 
Here in Figure 12, which explains the answer to the question, does the contribution of the franchisor to educate the franchisee about quality and its standards has a role in their application and then contribute to the sustainability of the contract? The answer was strongly agree exceeding by $70 \%$ and the agree by $29 \%$. We therefore emphasize the importance of the role of the franchisor to educate franchisees. The integration of individuals in the organization contributes effectively to the standards application.
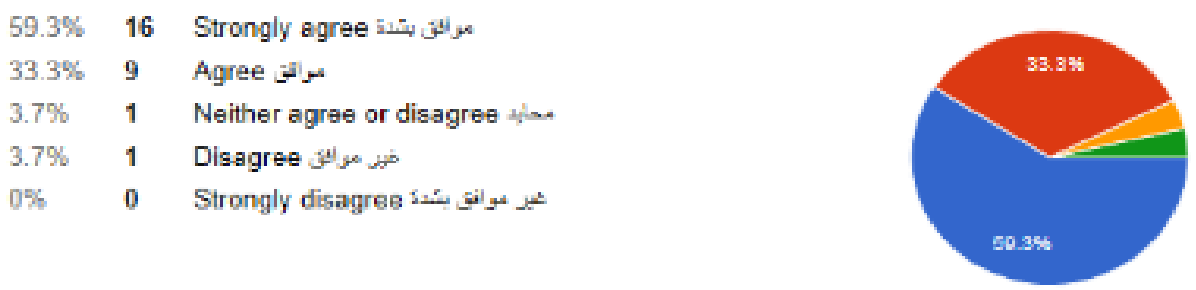

Figure 13

The form number 13 came to show the importance of integrating of individuals and their participation in decisions as effective members in applying quality standards. The answers varied between strongly agree by $69 \%$, and agree by $33 \%$, and the neutral and the disagree came in the same percentage by $3 \%$.The teamwork existence ready to apply quality standards
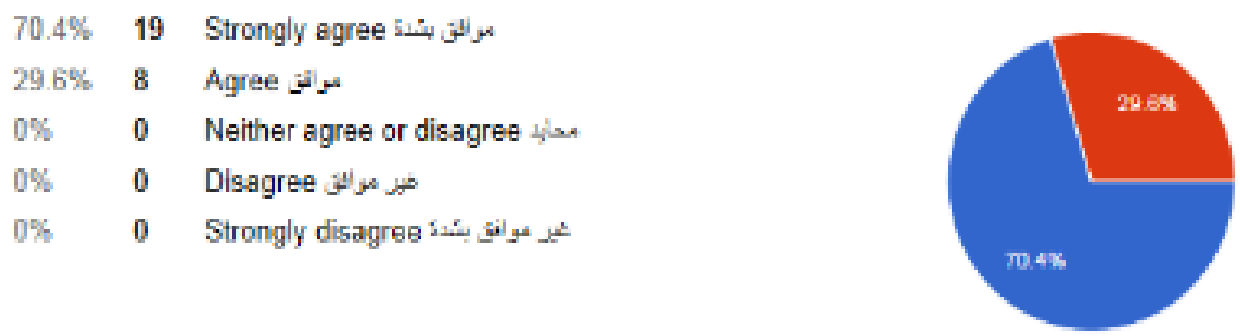

Figure 14

The form number 14 which we raised the question that does the existence of a working team ready to apply those standards has an actual role in the application or not? Where the strongly agree came by $70 \%$, and the agree by $30 \%$, referring to the importance of the psychological and scientific preparation of the teamwork.

\section{The commitment degree with the required standards is fundamental to both parties}
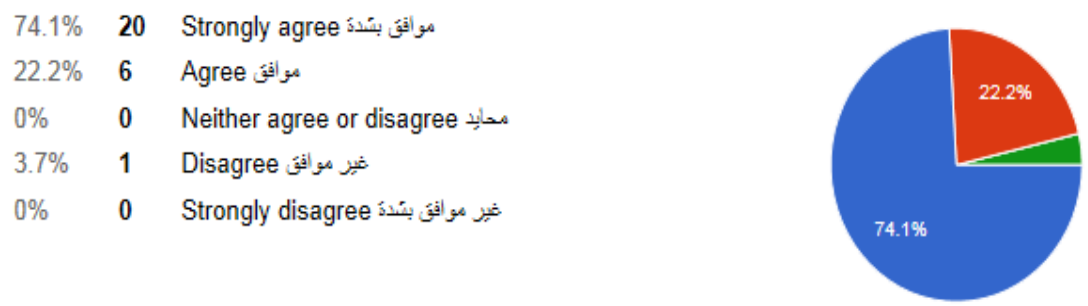

Figure 15 
The form number 15 explains the answers to the question: What is the degree of commitment with the standards required by the parties to the contract? Are they fundamental or secondary?

The answer which indicated that it is fundamental with strongly agrees by $71 \%$, and agrees by $22 \%$, and an orphan answer turned out to be a secondary degree of disagrees by $3 \%$.

The quality standards application is not commitment except in the processes that are provided to the final customer
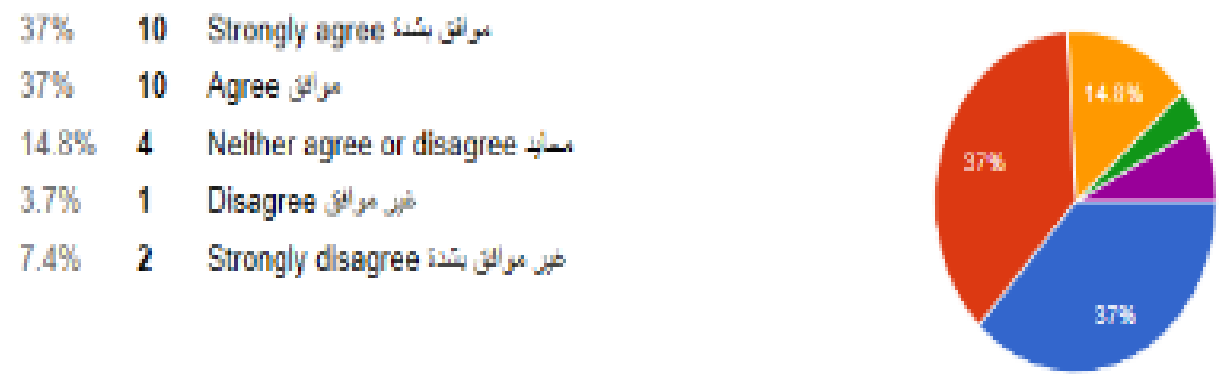

Figure 16

The form number 16 came to answer the question: does the application of the quality standards (TQM) is not commitment but only in the processes that are provided to the final customer? Where the answers varied and the strongly agree came at the first rank

What contributes to the application is that the final contract should be signed only after the franchisor has been know of the quality application plan by the franchisee.

The form number 17 explains the extent of the relation between the application of standards and the franchisor being informed of the quality application plan by the franchisee before signing the contract. The answers came equal for the important informing with strongly agree and agree by $37 \%$ for both groups and this is a clear indication for high importance of this matter.

The operational evidences existence that are known to the teamwork contributes to the actual application of the standards.

The form number 18 explains that the existence of operational evidences that are known to the franchisee teamwork contributes to the actual application of standards that the largest percentage was for the strongly agree by $74 \%$, and the list was followed by two groups that are the disagree and the strongly disagree by $0 \%$. This is due to the fact that the operational guide serves as a guide in applying the standards.

It is needed to identify the target groups of the product or service to determine the importance of the quality application importance of quality and the vice versa.
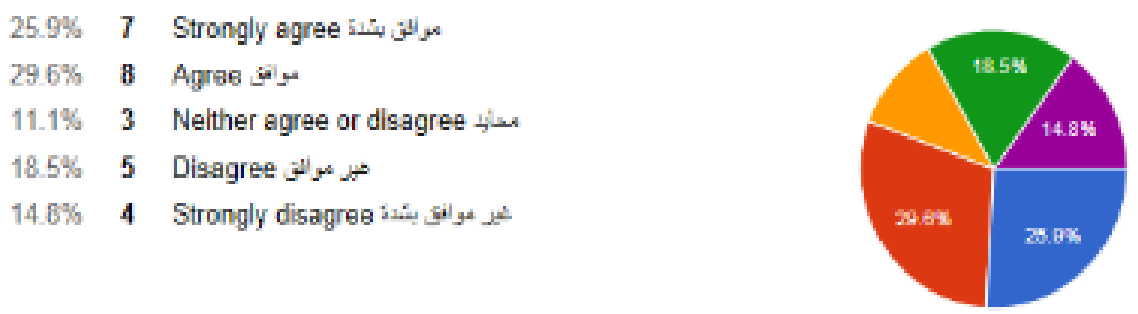

Figure 19

The form number 19 came to answer the question: Is it necessary to identify the target group of the product to see 
how important the quality application is and the vice versa? Where the answers varied and the agree came in the first rank by $29 \%$, and the strongly agree by $26 \%$, in the second and third rank came the disagree by $18 \%$, indicating that there is a radical difference in the answer to this question and this is due to the culture and values of the institution .

The franchisee commitment to submit periodic reports for the improvement contributes to the sustainability of the franchise contract
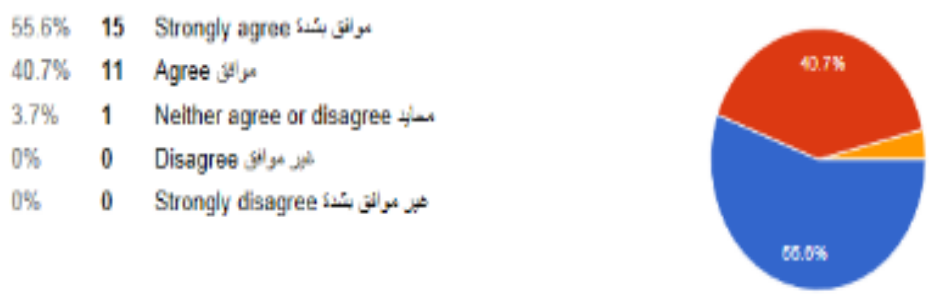

Figure 20

The form number 20 explains that the franchisee commitment to submit periodic reports for continuous improvement contributes to the sustainability of the franchise contract? The answer was strongly agreed by $56 \%$, agree by $11 \%$. It contains a clear statement for the importance of the reports .

The franchisee stipulation for franchisor to deliver disclosure documents has a role in sustainability the contract
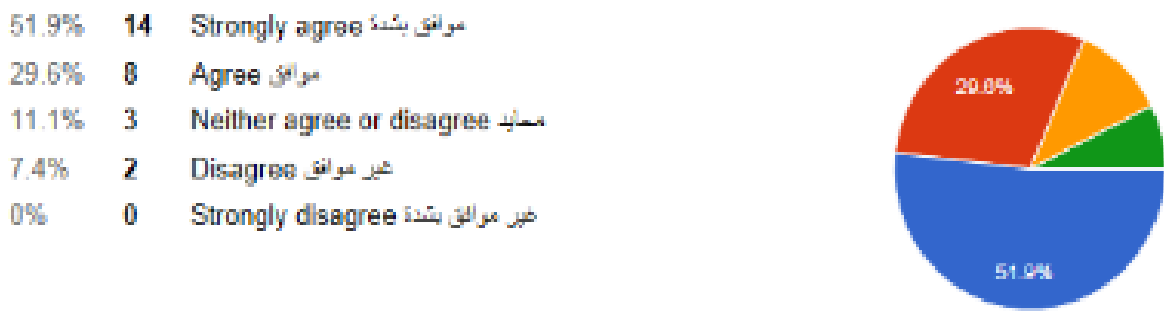

Figure 21

The form number 21 came to answer the question: Does the franchisee stipulation to franchisor deliver disclosure documents have a role in sustainability the contract. The answers variation in the importance of delivering disclosure documents, which often reach 13 documents, it is strongly agreed in the first rank by $60 \%$, and agreed by $27 \%$, in second and third rank the neutral came by $11 \%$, this is of course due to the importance of requesting disclosure documents to be the investment in it is very transparent.

Stipulating of the franchisor for the franchisees participate in training courses applied to quality is one of the factors in the success of the franchise contract. 

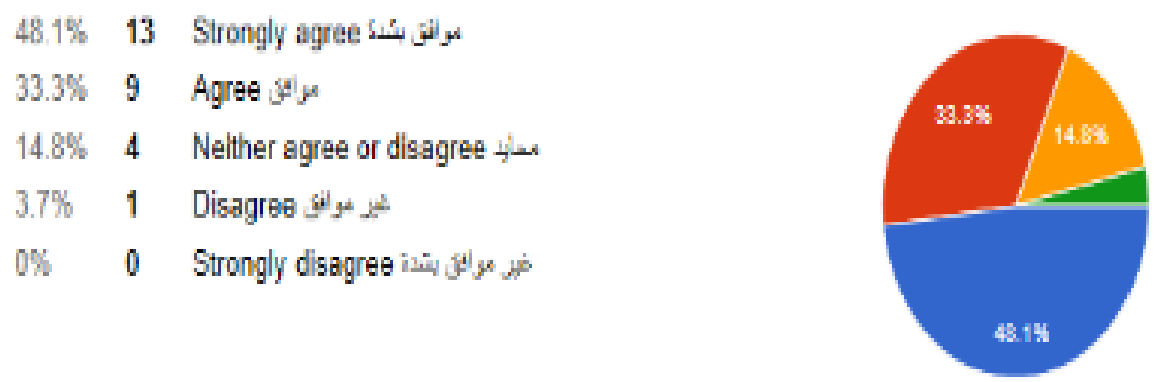

Figure 22

The form number 22 came to answer the question: Does the franchisor stipulation for franchisees to participate in training courses be one factor in the success and sustainability of the contract? Where the answers varied and the strongly agree came in the first rank by $48 \%$, and the agree by $33 \%$ came in the second rank. From the point of view of the researcher it may not be a basic stipulation as it is guidance.

Providing all training services specialized in the brand by the franchisor facilitate the franchisee to work efficiently.

$$
\begin{aligned}
& \text { 70 47 } 19 \text { Strongly agres }
\end{aligned}
$$

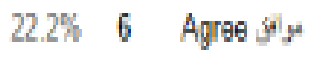

$$
\begin{aligned}
& 7.4 \% 2 \text { Neither agree or disagres }+4 \\
& 0 \% \text { Disigron } 0
\end{aligned}
$$

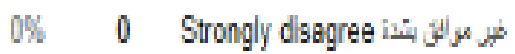

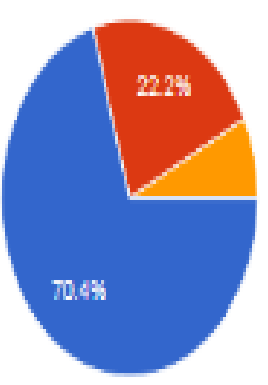

Figure 23

The form number 23 explains that: Does the training services specialized in the brand by the franchisor facilitate the franchisee to work efficiently? Where the answers varied and the strongly agree came at the first rank by $70 \%$, and the agree in the second rank by $22 \%$. This is due to the importance of logistic services which are provided and committed by the franchisor.

The treatment of franchisees as partners is a success reflected on the franchisees to preserve the trademark.

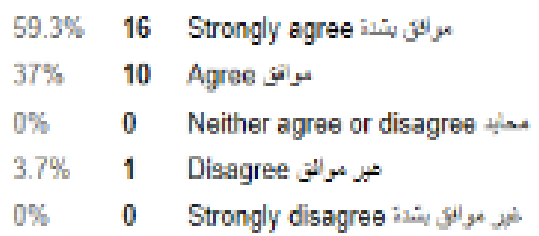

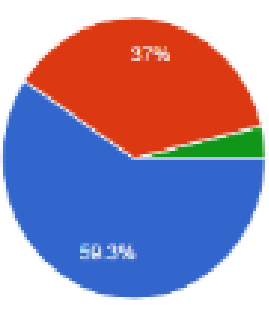

Figure 24 
The form number 24 answers the question: does the franchisor of franchisees treatment as partners are success reflected on the franchisees to preserve the trademark? The strongly agree came in the first rank by $85 \%$ and the agree in the second rank by $14 \%$. This clarifies the importance of friendly treatment and its impact on formal treatment and stipulations.

The affiliation of the franchisee to the trademark contributes to the keeping of the applicable quality standards.
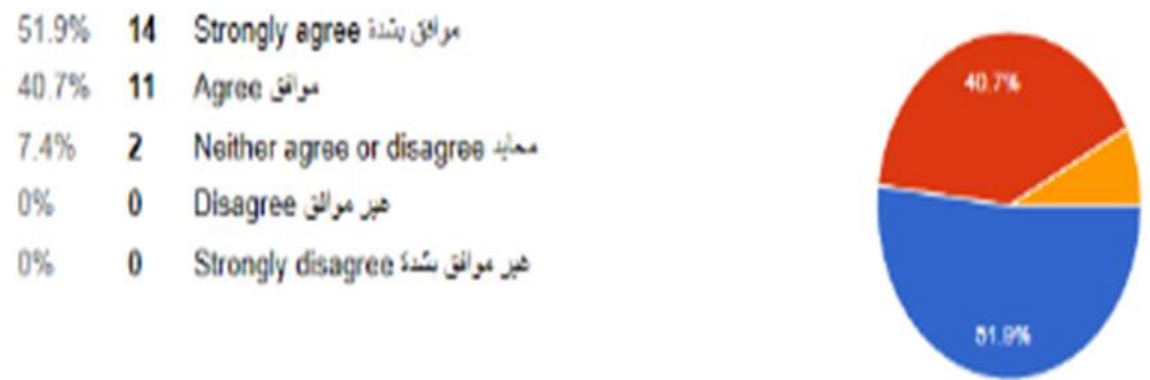

Figure 25

The form number 25 answers the question: Does the affiliation of the franchisee to the trademark contributes to the keeping of the applicable quality standards by the franchisor? The strongly agree came in the first rank by 59\%, and the agree by $37 \%$ in second rank. This is due to that whenever the franchisee deals with the trademark as his own is whenever the results are positive.

\section{Data Analysis and Findings}

\subsection{Results and Recommendations}

\section{Introduction}

This chapter clarifies the based conclusions as mentioned in conclusion section, and upon the conclusions, the recommendations arise, as well as, to get the objectives, the chapter will consist of two sections, conclusions and recommendations.

\subsubsection{Firstly: Results}

\section{Main results:}

1- The study side that the agreement on obligation with application of total quality standards and its relation with the sustainability of the franchise contract was higher.

2- The study side that the parties relation should be integrative where each party completes the standards which participate in the sustainability of the franchise contract.

3- The results concluded that the logistic services, if applicable, the degree of obligation with application of quality standards will be higher.

4- The statistical analysis pointed out that the franchisee should care about all targeted categories for insuring the quality.

5- The results concluded that quality culture should be understood and practiced by teamwork.

6- There is a significant evidence supported that if the documents of disclosure are existed, there will be a real obligation with application of standards.

\subsubsection{Second: Recommendations}

According to conclusions and results, there are some recommendations as the following:

1- Enhancing the application of total quality standards in the franchiser and franchisee institutions.

2- Devoting efforts and logistic services which will participate substantially in the sustainability of the franchise contract. 
3- Avoiding the division of targeted categories in the final product in related with quality assurance.

4- Spreading quality culture between the teamwork.

5- Working transparently and clearly between the parties.

\section{Conclusion}

The study side that the agreement on obligation with application of total quality standards and its relation with the sustainability of the franchise contract was higher. The study side that the parties relation should be integrative where each party completes the standards which participate in the sustainability of the franchise contract. The results concluded that the logistic services, if applicable, the degree of obligation with application of quality standards will be higher. The statistical analysis pointed out that the franchisee should care about all targeted categories for insuring the quality. The results concluded that quality culture should be understood and practiced by teamwork.

There is a significant evidence supported that if the documents of disclosure are existed, there will be a real obligation with application of standards.

According to conclusions and results, there are some recommendations as the following:

Enhancing the application of total quality standards in the franchiser and franchisee institutions.

Devoting efforts and logistic services which will participate substantially in the sustainability of the franchise contract.

Avoiding the division of targeted categories in the final product in related with quality assurance.

Spreading quality culture between the teamwork. Working transparently and clearly between the parties.

\section{References}

2015 Top Franchises from Entrepreneur's Franchise 500 List. Entrepreneur. Retrieved 22 March 2015.

Ahmed, A. (2010). Quality culture.

Ahonen, G., \& Hussi, T. (2002). Managing intangible assets - a question ofintegration and delicate balance. Journal of Intellectual Capital, 3(3).

Amit, R., \& Shoemaker, P. (1999). Strategic assets and organizational rent. Strategic Management Journal, 14, 22-46.

Fadil, A. (2010). Extent of obligation with total quality standards.

Khasfan, A. (2007). Agencies' contracts.

Maha, A. (2009). Total quality and its applications.

Mahmoud, R. Thought of quality.

Majid, O. (2009). Franchise.

Manual on Technology Transfer Negotiation (A reference for policy-makers and practitioners on Technology Transfer). (1996). United Nations Industrial Development Organization, Vienna, 1990.

Nasser, A. (2006). Obligation contracts.

Retrieved June 6, 2017, from Franchise-chat.com

\section{Copyrights}

Copyright for this article is retained by the author(s), with first publication rights granted to the journal.

This is an open-access article distributed under the terms and conditions of the Creative Commons Attribution license (http://creativecommons.org/licenses/by/4.0/). 